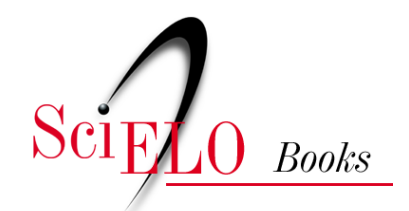

\title{
Machado de Silviano (o texto de Estela para o pai)
}

\author{
Ana Chiara
}

\section{SciELO Books / SciELO Livros / SciELO Libros}

CHIARA, A. Machado de Silviano (o texto de Estela para o pai). In: WERKEMA, A.S., ROCHA, F.C.D., and OLIVEIRA, L.D., eds. Literatura brasileira em foco VIII: outras formas de escrita [online]. Rio de Janeiro: EdUERJ, 2018, pp. 28-43. ISBN 978-85-7511-487-2. https://doi.org/10.7476/9788575114872.0003.

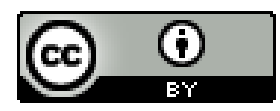

All the contents of this work, except where otherwise noted, is licensed under a Creative Commons Attribution 4.0 International license.

Todo o conteúdo deste trabalho, exceto quando houver ressalva, é publicado sob a licença Creative Commons Atribição $\underline{4.0}$.

Todo el contenido de esta obra, excepto donde se indique lo contrario, está bajo licencia de la licencia $\underline{\text { Creative Commons }}$ $\underline{\text { Reconocimento 4.0. }}$. 
Ana Chiara

Machado de Silviano (o texto de Estela para o pai) 
Repito-me: no palco, o mímico performa ações incompletas. Na plateia, o espectador completa-as. É o único modo de compreendê-las e de lhes emprestar significado.

(Silviano Santiago, p. 245)

Crianças, a guerra é um tiro a esmo. O que te confunde é a natureza do meu jogo (Rolling Stones)

Prepara

(O Show das Poderosas, Warner, Anitta, 2013).

\section{Vibrando em modo avião:}

Tudo é vagina. É disso que se trata. Da/do racha absurda/o. Do corpo aberto. Da água escorrendo. Desvios. Folhas úmidas. Refolhos. Dobras. Rosas roxas. Escuras de sangue pisado. Garganta profunda. Açaí. Água forte a Bandeira. Dali brotam as leituras rasuradas, em golfadas: a vida, a água viva, a origem do mundo de Courbet. Gorgomilos inflamados. Gritos presos nas gargantas das Capitus, Estelas, Carolinas. 
No final de Yayá Garcia até hoje me espanta o diálogo entre pai e filha.
Que pedia agora ao pai? Pouca e muita cousa; pedia que a acompanhasse, que cessasse a vida de dependência e servili- dade em que vivera até ali; era um modo de a respeitar e res- peitar-se. O pai escutava-a atônito: - Tu chegaste a amá-lo! Exclamou ele. Não o aborrecias? Amaram-se? E só agora sei... Bem digo eu; tu és uma fera.[...] (Assis, 1977, p. 508).

Tu és uma fera! Que se esqueçam os acontecimentos narrativos, as referências da história. A exclamação do pai reverbera na memória. Estela sai das sombras onde se perde no romance, uma heroína que renuncia ao amor para aparecer como "fera", algo irreconhecível aos olhos do pai. Um enclave narrativo. Um ato falho do mímico misógino.

Esta leitura vibra em modo avião. Medo. É o estalo de um tiro a esmo. Uma bala perdida. Um furo numa barriga. Um parto monstruoso. É deste lugar que sai o modo de ler. Da loca, do buraco de uma mulher como um bebê ainda sujo e ferido a bala. Ele irá morrer. A mulher presta atenção às mulheres como o carrapato atraído pelo ácido butírico. Seu modo de ler se asfixia num universo de sombras e rasuras. Portas estreitas por onde saíram Capitus, Estelas, Carolinas. Ela se enfia pela porta estreita da sororidade e reivindica alguma atenção para as mulheres que se esgueiram nas sombras onde $o$ amor é devoção entre homens, onde impera a amizade intergêneros. Ela está uma fera.

Esta leitura é uma boca aberta, um rasgo, uma ferida, uma fenda e um vagido, quer livrar-se da servilidade: ela quer libertar o pai. 


\section{Dar um corpo. Que corpo?}

Em 2014, Silviano Santiago lança o livro Mil Rosas Roubadas, tributário de uma longa amizade, em que o futuro "biografado" - o autor/narrador - teve de tomar o assento de seu biógrafo Ezequiel Neves (o "Zeca") que morreu sem ter cumprido uma tarefa. Livro de amor e saudade. Livro de desejo incontentado. Livro de um sobrevivente. De um viúvo. Em entrevista concedida, Silviano Santiago, para se opor ao retratismo biográfico, declarou - "uma autêntica biografia da vida interior".

A figura do sobrevivente paira também no livro seguinte sobre Machado de Assis. Deu-se, portanto, na arte o encontro de dois viúvos, dois sobreviventes. Uma viuvez de amigo (Silviano Santiago), outra viuvez de esposo (Machado de Assis). Em 2017, o escritor, crítico e professor mineiro lançou Machado, mais uma de suas articulações ensaísticas sobre vida e ficção romance, em que recorta um período difícil e dissolvente da vida do monstro intelectual que foi o autor fundador da Academia Brasileira de Letras e no qual compõe painel memorialista da vida da medicina homeopática, da vida da cidade do Rio de Janeiro e da vida da criação como doença.

Neste mapa ampliado de uma vida, cobrindo tantos aspectos, a criação pode ser vista travestida em "pequenas ausências", eufemismo para as crises epiléticas do patrono das letras, permitindo uma leitura delas em relação com os bastidores da criação do artista. Deste modo, é pela dobra (doença/criação) que Santiago costura o lugar de anterioridade, poço escuro dos afetos, dos fantasmas, a "lousa mágica do inconsciente" (como Santiago gosta de se referir) do que se capta não pelo pensamento, mas pela vida sensível, pelas marcas impressas e indeléveis dos fluxos do exterior e interior, pelos estados do corpo. Aonde iria o ar composto, o pudor, o trato civil de 
presidente da Academia quando à sua revelia tudo se contraía e ato contínuo se distendia? Aonde? A que lugar secreto, lugar do crime da criação, onde o escritor caía quando o corpo e a mente lhe fugiam ao controle. Um espasmo e um pasmo. Uma baba que entorna. Um curvar o pescoço que põe a vida de viés. $\mathrm{O}$ ataque força que o olho se desloque para dentro em êxtase. Essa "ausência" poderia ser uma destinação ou uma danação para aquele que escreve? Onde estaria o homem quando seu corpo estivesse entregue à "fera" que se esconde em cada um? Este não-lugar-este útero? "O camarim é semelhante a um poço profundo não armazena água, mas tinta negra” (Santiago, 2017, p. 263).

Santiago aproxima o ataque epilético cujo eufemismo usado por Machado de Assis em sua correspondência também podia ser a expressão "pecado original" à cura, por meio da arte a partir das possibilidades de sentido que apontavam para as convulsões: "De mim, vou bem, apenas com os achaques da velhice, mas suportando sem novidade o pecado original" (Santiago, 2017, p. 268). Eis os desdobramentos capturados pelo biógrafo:

Poucas semanas depois de ter escrito a carta em que o pecado original metaforiza o corpo epilético para em seguida o desmetaforizar recorrendo aos remédios receitados pelo médico que, se não trazem a cura, trazem o controle da doença, Machado de Assis retorna ao tópico. Desta feita, associa o controle da epilepsia (ou do pecado original para continuar no campo semântico da metáfora) à função primordial da arte para ele, tese que Mario de Alencar endossa. Este é ainda o destinatário da carta escrita por Machado. Copio: 'Também eu tenho desses estados de alma, e cá os venço como posso. A arte é remédio e o melhor deles.' (p. 268) 
Cura ou veneno? Ataque, achaque, convulsão, gozo, Santiago tem a generosidade de devolver o corpo aos escritores reprimidos. Foi assim na cena criada com Graciliano, cuja ereção na praia corresponde ao título à desrepressão do corpo um dos motivos do romance Em Liberdade (1981). Aconteceu assim com Machado de Assis, personagem do romance Machado em suas "ausências" tão próximas do estado de convulsão erótica. Santiago resgata - para o leitor - o corpo vulnerabilizado/erotizado de Machado em convulsões epiléticas, assim como Didi-Huberman (2015) leu o movimento convulsivo dos corpos das histéricas, em suas performances teatrais para Chacort, e como Warburg fez com o das bacantes. Santiago (2017, p. 269) nos ensina que a beleza convulsiva da arte se conquista desde os bastidores de um corpo entregue a si mesmo, um corpo acéfalo, o corpo da fera:

Entre a alopatia e a homeopatia, entre o dr. Miguel e o dr. Tomás, o vocábulo "remédio" sai, de repente, do campo estreito das cartas trocadas naqueles meses e da medicina a fim de se adentrar pela definição do que seja a atividade artística para o escritor epiléptico, ou seja, a função da arte no processo de criação da beleza convulsiva.

\section{A Ferocidade das Fêmeas}

Elas [as onças] sabem que sou do povo delas. Estou onçando, estou virada na Maria Maria. Estou chegando minha pata devagarinho no peito do Mestre, do pai das letras brasileiras. Eu tava com as unhas... [...] Aí eu tinha uma câimbra no corpo todo, sacudindo; dei acesso (Ana Chiara com Guimarães Rosa).

Em 2017, Santiago publica Genealogia da Ferocidade, livro em que faz uma leitura "desconstrutora" da recepção da obra Grande Sertão: Veredas, de Guimarães Rosa. Esse livro é a "bioescrita" de um livro - como antes o crítico tinha se ocupado de Macunaíma - 
recorde-se o artigo de Nas malhas da letra (ensaios), de 1989, quando fez um apanhado de como o livro foi entendido pela crítica. No caso de Grande Sertão, uma recepção crítica que tentou domesticar, segundo Santiago, por leituras comparativas, o caráter monstruoso (a palavra vem do latim monstrum, "sinal do que está por vir, presságio", ligado ao verbo monere, "avisar, advertir”). Em sua leitura, numa direção diversa, o crítico deseja recuperar o nervo do processo de hibridação, em Meu tio o Iauraetê, conto de Guimarães Rosa, de um imaginário feito de algo de humano, mas também da ordem da animalidade, do corpo viril vivo, pulsátil desejante de Riobaldo/Reinaldo e do corpo macho/feminino de Diadorim morto, tornado larva luminosa, ninfa, corpo de formas arcaicas, sobreviventes também como o enclave histórico, geográfico, ambiental do Liso do Sussuarão.

Esta leitura está tendo um ataque epilético, um chilique, um "me segura que vou dar um troço", está intoxicada e procura nelas um nexo, um elo entre a figura da mulher nestes livros - suas sombras, sua ausência - e a da fera, da forma inconsútil de uma larva. Esta leitura é uma "ramificação sanguínea" da fera riscada nos livros de Machado. É parente da onça Maria Maria, do meu tio o Iauaretê. Esta leitura quer onçar. Nela a mulher é o liso do Sussuarão. É um locus tenens. Um enclave arcaico e monstruoso. Um mapa em disseminação. É dirigida a pai. Pai eu te escrevo das sombras, de um campo destroços. Pai, por que me abandonaste? (ana chiara)

\section{A mulher à sombra}

No conto Todas as coisas à sua vez (Abecedário) de 2003, do livro Histórias mal contadas (2005) de Silviano Santiago, "homenagem ao notável escritor" Graciliano Ramos pelo aniversário de cinquenta 
anos de sua morte, escrito ao estilo "graciliano" por Silviano Santiago que tão bem soubera usá-lo no livro Em liberdade (1981): leio um comentário ou nota com referência à mulher na obra de Machado de Assis,

A mulher se esconde na sombra. Por que evita a luz? Por que não se desnuda? Por que nunca se dá a conhecer? Por que é segredo? //A mulher é Maia. Sua arma mortífera é o pudor. // Machado desvendou o mistério - o segredo da mulher. Só não passou a fórmula a nós, homens (Santiago, 2005, p. 120).

Mas haveria este mistério? Trata-se obviamente de uma pergunta lançada ao lugar comum masculino, reproduzido pelo escritor-personagem Graciliano. Difícil que - se houvesse ou se houver mistério - Machado o tivesse "desvendado", de temperamento misógino creio que o circundou e o recobriu com mais camadas de desconfiança ou, hipótese provável, reafirmou o mito do mistério como forma de afastamento e desconfiança. Por que este mistério teria uma "fórmula"? Por que interessa ao escritor Machado recobrir a mulher com camadas de sombras, como rasuras?

***

Em Walter Benjamin pode-se ler:

Ou seja, em sua conclusão, a criação torna a parir o criador. Não segundo a sua feminilidade, na qual ela foi concebida, mas no seu elemento masculino. Bem-aventurado, o criador ultrapassa a natureza: pois esta existência que ele recebeu, pela primeira vez, das profundezas escuras do útero materno, terá de agradecê-la agora a um reino mais claro. A sua terra natal não é o lugar onde nasceu, mas, sim, ele vem ao mundo onde é a sua terra natal. É o primogênito masculino da obra, que foi por ele concebida. (1987, p. 277)

(Atétu, Benjamin? Atribuindo à mulher o lugar da natureza? Pois eu proponho uma leitura como reação uterina. O lugar escuro do útero, 
sob ação das revoltosas erínias, estes elementos de feminilidade arcaica reivindicamafigura doquenão está. Figura quesevarreu para as sombras. Como a personagem de Machado de Assis em Yayá Garcia, Estela, minha leitura filha do romance Machado de Silviano, quer libertar o pai da melancolia e da servilidade à razão iluminista, libertá-lo das regras de civilidade da Academia Brasileira de Letras, quer libertá-lo de sua misoginia, de seu medo da mulher. Quer libertá-lo da admiração bem comportada (e desconfiada) por tantas personagens-femininas que retratou sob os véus do mistério, do enigma, da desconfiança.)

No romance Machado, persiste a imagem da mulher na sombra, da mulher à sombra. Santiago nos deixa frente a frente a isso, por meio da estratégia de pôr em evidência um sistema de rasuras ficcionais, como se verá na sequência, envolvendo o rascunho do livro Memorial de Aires, corroborado por trechos da correspondência entre o escritor do Cosme Velho e seu pupilo Mario de Alencar. Estas rasuras vão dar a medida do clima de desconfiança com que é tratada a mulher - vamos conceder: àquele tempo - através também de um jogo narrativo em que os nomes femininos vão se riscando, vão se metamorfoseando nas figuras de Carmelita, Carmo, Fidélia, Maia, Pandora, Maria, Carolina - este último o nome interdito ficará para sempre a mulher atrás do homem notável.

(Ele a jogou no túmulo e a cercou de flores, para ser resgatada por Silviano no rosto da mulher do povo - a sem nome. A da beleza convulsiva) ana chiara.

Na narrativa do romance, o capítulo "VII: Ressurreição dos Mortos", Silviano Santiago deixa ver que o tratamento dado à mulher na obra de Machado é marcado pela desconfiança dos personagens 
masculinos através de uma metafórica da construção civil bastante peculiar ao homem versus metafórica na qual a mulher será o elemento secundário. Se o homem é um monte de "pedras soltas", a mulher, cimento que o cola, tem "trejeitos camaleônicos". Na verdade, essa parece ser a ótica de Machado de Assis e não só de seus personagens homens. Silviano Santiago (2017, p. 247) é cuidadoso:

A reflexão íntima do protagonista masculino de Machado de Assis é produto das pedras soltas do seu temperamento e, ao se endereçar às incertezas do amor, tem seu ponto de partida nas primeiras tentativas de escrever literatura. O olhar doente e torto do apaixonado ganha então adjetivo. É de ciumento.

Preciso acompanhar a extensa digressão de Silviano Santiago (2017, p. 258), referindo-se ao processo de rasuras de Memorial de Aires: "Lúcia Miguel Pereira se refere às hesitações e correções que traduzem a insegurança do romancista (Machado) quanto ao nome próprio a ser dado às duas protagonistas femininas - a velha dona Carmo e a jovem viúva Fidélia”. Continua seguindo palavra por palavra Lucia Miguel Pereira: "[...] as trocas de nome entre D. Carmo e Fidélia são frequentíssimas, são mesmo quase a regra. Em 393 das 468 páginas do manuscrito existem 167 dessas trocas; cada vez pensava numa, a figura da outra lhe acudia ao espírito, como se as confundisse. Confundi-las-ia também o coração?”. Santiago (p. 259) conclui: "O manuscrito quer confundir dona Carmo e Fidélia”. Avança o raciocínio: “(Machado) perde o controle no julgamento racional sobre as amadas viúvas da sua vida?". Segue Silviano Santiago (p. 260): "O enigma proposto pelo exame do copião de Memorial de Aires e pelo conhecimento da vida do romancista do chalé do Cosme Velho diz que as duas são uma só." As duas, prossegue Santiago (p. 261), seriam na verdade três, diz num parágrafo curto: "Essa figura (uma figura feminina única) seria o côncavo da vida 
amorosa, sua raiz, de onde brota uma e outra protagonista”. Depois completa a imagem: "Coexistem num único e terceiro nome próprio, que tem de ser rasurado, borrado pelo escritor, para que dois outros e diferentes nomes próprios emerjam da mancha negra da escrita e existam como protagonistas singulares do Memorial de Aires".

Tomar uma pela outra, rasura todas. A mancha côncava me remete à forma útero, pois não foi de lá que começamos esta leitura? Por que trocar uma por outra? Todas se confundem no seu coração? (ana chiara)

O sistema de rasuras também é observado por Mario de Alencar, em torno do nome "riscado" e substituído de Carolina, a esposa morta, conforme o narrador (p. 266) explicita: “O mímico não pode deixar de ser cauteloso e precavido e é por isso que, em paralelo à indiscrição do septuagenário, existe um delicado sistema de rasuras":

Iluminado pela descoberta, Mario se reconhece leitor privilegiado pelo mestre e, ao mesmo tempo e convenientemente, se resguarda e se isola dos futuros leitores do romance. Só ele pode deter e detém a chave para entrar pela porta da quarta dimensão, cuja chave é de uso exclusivo de Carolina (Santiago, 2017, p. 265).

Mario se torna o leitor primeiro e confidente de Machado, lugar antes ocupado por Carolina. Machado o seduz com a promessa de um segredo: "Aproveito a ocasião para lhe recomendar muito que, a respeito do modelo Carmo, nada confie a ninguém; fica entre nós dois" (p. 265).

(Ai, Jesus! "Entre nós dois" é quase uma frase enamorada, muito mais quando o nome rasurado neste lugar desconfortável é o de sua esposa morta) ana chiara. 
Derrida, cujos textos foram difundidos nos cursos de Silviano Santiago na PUC-Rio, escreve sobre Babel dizendo-o um nome próprio que se torna inatingível. Este é o circuito produtor do signo, uma cadeia de substituições da "coisa" criando uma ilusão de presença. "Babel: antes de tudo um nome próprio, seja. Mas quando dizemos Babel, hoje, sabemos o que nomeamos?” (Derrida, 2002, p. 11). Ao substituirmos Babel por um nome de mulher, sabemos o que nomeamos? O nome Carolina, lido por Mario no segredo da rasura, uma torre erguida entre os dois homens, dois escritores, dois temperamentos neuróticos dados a achaques e "ausências": Machado de Assis e Mario de Alencar.

A dobra do significante, da letra, este MMdeA num ringue cheio de pudor, celebra a união dos dois escritores nos ataques convulsivos. "Estes dois..." diria Nelson Rodrigues. A mulher de Mario Alencar fica apartada na casa grande. Sozinha. O pupilo vai para a casa próxima à do Mestre. Unidos na doença, são nevróticos/neuróticos, os excessos de calor ou frio provocam neles reações físicas incontroláveis. São térmicos, como na releitura de Grande Sertão:Veredas, Santiago aponta a respeito dos amores entre Riobaldo e Reinaldo/ Diadorim que também opera por rasura ou troca: “[...] Agora, destino da gente, o senhor veja: eu trouxe pedra de topázio para dar a Diadorim; ficou sendo pra Otacília, por mimo; e hoje ela se possui é em mão de minha mulher!” (Rosa apud Santiago, 2017, p. 85).

(Eu hein, Rosa...Esta história está mal contada, contada pela metade. Ou sou eu que entro em delírios de leitora frenética e misturo as cartas, nossas cartas? Não me chama de louca que te acuso de gaslighting) ana chiara. 
Santiago ainda neste capítulo do livro Machado traz à baila o caso da bacia: anotação de Machado junto ao relato das "ausências". Aos leitores de Machado, ele arrisca: “[...] a anotação, que apenas me direciona a significações subjetivas e aleatórias”(p. 279). Significações que dirá adiante conformarem um "complexo sistema de alusões" (p. 280). Vai buscá-las em Esaú e Jacó numa bacia de esmolas para referi-las ao caráter desonesto do capitalista brasileiro/do irmão das almas. Impressiona-me o termo bacia, este lugar alquímico e gestacional. É pelas rachaduras digressivas que Machado escreve com o corpo feminino, conforme seu biógrafo (p. 281) anota: "corte, abertura e digressão, se somados, são a forma mais autêntica e corajosa de Machado interromper [...]”. Eu abrevio a metáfora por minha conta: ao interromper a narrativa linear tradicional masculina, Machado usa sua bacia, o outro lado de sua máscara de Janus. Natividade corpo materno de Machado - , no romance, vai parir três monstros: Pedro e Paulo, os fracos e indecisos, e Nóbrega, o ladino e corrupto irmão das Almas, este ser de rapina. Por sua intromissão na narrativa, de sua bacia, saíram os abortados: os homens fracos.

\section{A mulher do povo}

Mas, avanço, em busca da mulher que ampara o homem ao longo do livro de Santiago, imersa nas sombras, sem se deixar ver. No capítulo "Transfiguração", personagens homens se apaixonam por uma tela que dá nome ao capítulo, a tela "A mulher do povo", de Rafael Sanzio que será admirada por Sthendal, Machado de Assis e por outros. Silviano Santiago nos conduzirá pacientemente por essas leituras. Será o narrador do livro Machado, ou seja, Santiago na função autor/narrador que tirará das sombras a figura da mulher do povo num revirão gestáltico. 
Se, no romance Machado, as mulheres são aludidas, mantidas à distância, pelo olhar do narrador que capta a real situação da mulher na vida do Rio de Janeiro àquela época, será este olhar solidário contemporâneo que fará o movimento transfigurador da tela de Rafael alterando o sistema viciado da figura/fundo. Tudo neste capítulo tende às inversões. É na colina do Janículo, em meio à paisagem modesta, que Stendhal verá o quadro. O cruzamento de olhares masculinos (Sthendal, Joaquim Nabuco, Magalhães de Azeredo, Benito Pardo, Anton Raphael Mengs) sobre o quadro é sequencialmente recuperado, as leituras são intricadas e cheias de reviravoltas, sendo impossível aqui seguir passo a passo as descobertas de Santiago atribuídas a Machado. Seleciono, do capítulo, a menção do narrador a uma figura feminina do quadro de Rafael: "à frente da cena dramática, destaca-se uma mulher ajoelhada, de perfil. Figura enigmática, sua cabeça está virada para os apóstolos. Seria Pandora?” (Santiago, 2017, p. 404). Por obra de seu lado sismógrafo, Santiago vai perceber novas acomodações de figuras. É a dança da menina dos olhos em busca do que olhar, nos livros em que pesquisa, que revela o modelo da mulher magnífica do quadro da Transfiguração?

Trata-se de uma anônima. Uma mulher do povo que Santiago (2017, p. 411) repara ter sido reencontrada em esboços, desenhos. "Num segundo momento o crítico (Mengs) compara a figura da Virgem, representada na Sagrada Família, tela a óleo, ao desenho a lápis de uma mulher do povo, para contrastá-los”. Esse desenho não está exposto, foi Santiago que o tira dos arquivos do Museu do Louvre em suas leituras. Rafael, talvez apaixonado por uma mulher do povo, teve de torná-la sublime no quadro da Sagrada Família. Outro modo de rasura. Mas a este movimento, Silviano Santiago faz uma torção quando do quadro nos revela como a partilhar o punctum a real condição da modelo para a família. É a mulher do povo, a anô- 
nima, essa que será pintada por Rafael e que atiçará a curiosidade dos leitores atuais deste romance. Silviano Santiago a retira do plano de fundo para o plano de frente. Ela deverá a partir disso atiçar uma nova atitude dos expectadores do quadro, dos leitores de Machado, pelo olhar de Santiago. Ela é a nova Estela. A nova estrela. É fera.

É belíssimo o movimento!

(Respiro fundo. Abandono o livro, usei-o como quis. Nele, a lembrança de Estela ressurge com a mulher do povo. Está gloriosa! Ela diz: Pai, não se amofine, já estou indo libertá-lo de seus medos, de sua forma, de sua fórmula, de suas metáforas militares, suas parábolas, sua cauterização erótica, vamos cometer o incesto da arte, este pecado original, esta arrogância convulsiva, esta epilepsia, esta histeria, esta "gravidez psicológica". Vou te parir de novo em homem lavar, coisa fugidia, meio mole, indescritível, escuro como uma enguia, coisa escorrendo de dentro do meu corpo....vou te dar um buraco. Aquilo: uma racha. Uma fenda. Uma abertura a mais para te alimentar e te fazer feliz...Prepara!) ana chiara. 


\section{Referências}

ASSIS, Machado. "Yayá Garcia". Obra Completa, de Machado de Assis, vol. I, Rio de Janeiro: Nova Aguilar, 1994.

BENJAMIN, Walter. Rua de mão única. Trad. Rubens Rodrigues Torres Filho e José Carlos Martins Barbosa. São Paulo: Brasiliense, 1987, p. 277.

DERRIDA Jacques. Torre de Babel. Belo Horizonte: UFMG, 2002.

DIDI-HUBERMANN, Georges. Invenção da histeria: Charcot e a iconografia fotográfica da Salpêtrière. Trad. Vera Ribeiro. Rio de Janeiro: Editora Contraponto, 2015.

SANTIAGO, Silviano. Histórias Mal Contadas (contos). Rio de Janeiro: Rocco ed, 2005.

. Em Liberdade (romance). Rio de Janeiro: Rocco ed, 1981.

. Nas malhas da letra. Rio de janeiro: Rocco ed, 1989.

Anônimos (contos). Rio de Janeiro: Rocco ed, 2010.

. Mil Rosas Roubadas. São Paulo: Companhia das Letras, 2014.

. Machado (romance). São Paulo: Companhia das Letras, 2017.

Genealogia da ferocidade. Pernambuco: Companhia Editora de Pernambuco, 2017. 